\title{
Chiral Nano-Liquid Chromatography and Dispersive Liquid-Liquid Microextraction Applied to the Analysis of Antifungal Drugs in Milk
}

\author{
Chiara Dal Bosco ${ }^{1}$, Flavia Bonoli ${ }^{1}$, Alessandra Gentili ${ }^{1}$, Chiara Fanali ${ }^{2}$ and Giovanni D'Orazio ${ }^{3, *(\mathbb{D})}$ \\ 1 Department of Chemistry, Sapienza University of Rome, 00185 Rome, Italy; \\ chiara.dalbosco@uniroma1.it (C.D.B.); bonoli.1705434@studenti.uniroma1.it (F.B.); \\ alessandra.gentili@uniroma1.it (A.G.) \\ 2 Unit of Food Science and Nutrition, Department of Science and Technology for Humans and the \\ Environment, Università Campus Bio-Medico di Roma, 00128 Rome, Italy; C.Fanali@unicampus.it \\ 3 Istituto per i Sistemi Biologici (ISB), CNR-Consiglio Nazionale delle Ricerche, Monterotondo, \\ 00015 Rome, Italy \\ * Correspondence: giovanni.dorazio@cnr.it; Tel.: +39-0690672256
}

Citation: Dal Bosco, C.; Bonoli, F.; Gentili, A.; Fanali, C.; D’Orazio, G. Chiral Nano-Liquid Chromatography and Dispersive Liquid-Liquid Microextraction Applied to the Analysis of Antifungal Drugs in Milk. Molecules 2021, 26, 7094. https:// doi.org/10.3390/molecules26237094

Academic Editor: Petr Bednar

Received: 9 October 2021

Accepted: 22 November 2021

Published: 24 November 2021

Publisher's Note: MDPI stays neutral with regard to jurisdictional claims in published maps and institutional affiliations.

Copyright: (c) 2021 by the authors. Licensee MDPI, Basel, Switzerland. This article is an open access article distributed under the terms and conditions of the Creative Commons Attribution (CC BY) license (https:// creativecommons.org/licenses/by/ $4.0 /)$.

\begin{abstract}
A novel chromatographic application in chiral separation by using the nano-LC technique is here reported. The chiral recognition of 12 antifungal drugs was obtained through a $75 \mu \mathrm{m}$ I.D. fused-silica capillary, which was packed with a CSP-cellulose 3,5-dichlorophenylcarbamate (CDCPC), by means of a lab-made slurry packing procedure. The mobile phase composition and the experimental conditions were optimized in order to find the optimum chiral separation for some selected racemic mixtures of imidazole and triazole derivatives. Some important parameters, such as retention faction, enantioresolution, peak efficiency, and peak shape, were investigated as a function of the mobile phase $(\mathrm{pH}$, water content, type and concentration of both the buffer and the organic modifier, and solvent dilution composition). Within one run lasting $25 \mathrm{~min}$, at a flow

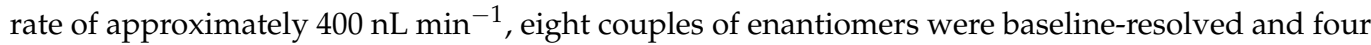
of them were separated in less than $25 \mathrm{~min}$. The method was then applied to milk samples, which were pretreated using a classical dispersive liquid-liquid microextraction technique preceded by protein precipitation. Finally, the DLLME-nano-LC-UV method was validated in a matrix following the main FDA guidelines for bioanalytical methods.
\end{abstract}

Keywords: antifungal drugs; chiral separation; nano-LC; dispersive liquid-liquid microextraction; milk

\section{Introduction}

One of the most important categories of pharmaceuticals is that of chiral drugs. Due to the difficulty and cost of synthesis, most of them are still marketed as a racemic mixture, although the pharmacological activity is often associated with only one enantiomer, with the other one being inactive or even harmful. An example of a group of chiral drugs widely used in clinical and veterinary medicine, as well as in agricultural practices, is represented by antifungal agents. They are grouped into four main chemical classes: polyene antibiotics, allylamines, fluoropyrimidines, and azole derivatives [1]. All azoles have the same mechanism of action, which consists of blocking the biosynthesis of ergosterol, a key component of the cytoplasmic membrane of fungi [2].

In farming practices, antifungal drugs are used to treat dermatophytosis or ringworm, mycotic abortions, and mycotic mastitis, especially in ruminants. Bovine mammary infections, usually caused by yeasts belonging to Candida, Cryptococcus, or Trichosporon genera, can become a chronic condition, with a negative impact on both the milk yield and quality. The great density of animals per unit area in modern housing can promote the spread of infection [3] and, therefore, high economic losses for the dairy industry. For 
this reason, the use of effective antifungal drugs is required. On the market, such drugs are available as racemic mixtures of various enantiomers, whose varied pharmacological activity can lower the drug's efficacy and increase the probability of side effects [3]. Moreover, improper administration or insufficient time for drug clearance can potentially lead to the occurrence of their residues in milk, with a risk of adverse effects on consumers. Thence, the determination of these agents, potentially occurring at trace levels in livestock products, is a crucial need.

Over the last decade, several chromatographic methods have been used for the chiral and achiral separation of azole antifungal drugs, including gas chromatography (GC) $[4,5]$, supercritical fluid chromatography (SFC) [6], liquid chromatography coupled with ultraviolet detection (LC-UV) [7,8], and liquid chromatography-mass spectrometry (LC-MS) [9-13]. Besides HPLC, the chiral separation of antifungal drugs has also been realized via miniaturized techniques such as nano-LC and capillary-LC (CLC) by using monolithic columns with an internal diameter (ID) of 100-150 $\mu \mathrm{m}$; the monoliths were manufactured by in situ copolymerization using different chiral selectors: $\beta$-cyclodextrin $(\beta-C D)[14,15]$, macrocyclic antibiotics, namely colistin sulfate [16], amylose 2,3 (3,5-dimethylphenylcarbamate)6-ethylphenylcarbamate [17], and single-walled carbon nanotubes (SWCNTs) [18]. In chiral analysis, electromigration techniques are considered powerful alternatives to HPLC and GC. Thus far, the enantiomeric separation of imidazole and triazole derivatives has been achieved in capillary electrophoresis (CE), mainly by adding CDs to the background electrolyte (BGE) [19-21].

However, the most important issue concerning the analysis of antifungal drug residues in milk is related to the complexity of this matrix, which is, at the same time, a biological fluid and food with the characteristics of three chemical phases: emulsion, colloidal suspension, and solution [22,23]. It contains all nutrients, including proteins, lipids, and lactose, as the main components that may interfere with analytical determinations. Therefore, the sample preparation step is crucial in order to remove most interfering compounds and to concentrate the drug residues. Thus far, only two papers dealing with the determination of azole antifungals in milk have been reported. Ebrahimpour et al. realized the simultaneous extraction of miconazole and clotrimazole by using three-phase hollow-fiber liquid-phase microextraction (HF-LPME), followed by GC-flame ionization detection (FID) analysis [5]. Yahaya et al. isolated three azole antifungals from milk by ultrasound-assisted emulsification microextraction combined with dispersive micro-solid-phase extraction (USAED- $\mu$-SPE), followed by the use of an LC diode array detector (DAD) [9]. In both cases, antifungal drugs were analyzed by achiral methods and determined as racemic mixtures.

Therefore, to the best of our knowledge, this paper is the first report on the enantiomeric determination of antifungal drugs in milk samples. To this end, lab-made silica capillary columns were packed with a polysaccharide-based stationary phase (cellulose 3,5-dichlorophenylcarbamate (CDCPC), covalently bonded to $5 \mu \mathrm{m}$ silica particles) for the chiral separation of eight imidazole derivates (miconazole, bifonazole, butoconazole, econazole, isoconazole, ketaconazole, sertaconazole, fenticonazole) and four triazole derivates (fluconazole, posaconazole, terconazole, voriconazole). Their nano-LC-UV analysis was preceded by dispersive liquid-liquid microextraction (DLLME), a procedure that is usually applied to treat water samples and is here combined with a previous clean-up to process milk samples. The whole method, based on miniaturized extractive and separative techniques, responds to the criteria of sustainability as regards Green Analytical Chemistry.

\section{Results and Discussion}

\subsection{Optimization of the Chromatographic Conditions}

A wide variety of chiral selectors have been used to separate fungicides [24]; however, chiral stationary phases (CSPs) based on polysaccharides (i.e., cellulose and amylose) have shown excellent recognition capability, especially when derivatized with phenyl moieties, such as phenylcarbamate groups modified with electron-donating or electron-withdrawing substituents. In this study, cellulose 3,5-dichlorophenylcarbamate was tested for the chiral 
separation of twelve azole antifungals. The separation was carried out on a capillary column packed with a no-commercial CDCPC by means of a lab-made nano-LC system. The CSP has the helical carbon backbone with phenylcarbamate moieties as side chains, providing a highly ordered chiral conformation that is able to form a reversible complex with the molecules of the target analytes $[25,26]$. The chiral discrimination allowed by the CSP depends on its hydrophobic, hydrogen bonding, $\pi-\pi$, and dipole-type interactions [27] The analytes selected in this study exhibit different values of hydrophobicity (see $\log \mathrm{P}$ and hydrophilic-lipophilic balance (HLB) in Table 1) and acidity (pKa); in particular, imidazoles are weak dibasic agents whose nature has to be considered in order to achieve their chiral separation. In this framework, parameters such as the composition of the mobile phase $(\mathrm{pH}$, buffer concentration, water content/organic modifier), the sample dilution solvent, and the injection volume were systematically studied by analyzing their effect on the retention factor (K), enantioresolution (Rs), chromatographic efficiency $(\mathrm{N})$, and chromatographic profile. The optimal experimental conditions were obtained through a suitable compromise between the best enantioseparation and the shortest analysis time.

Table 1. pKa, $\log P$, and HLB values of the studied antifungal drugs.

\begin{tabular}{cccc}
\hline Analyte & pKa & LogP $\left(^{(*)}\right.$ & HLB $^{\left.(*)^{* *}\right)}$ \\
\hline Fluconazole & 12.68 & 0.56 & 9.56 \\
Voriconazole & 12.7 & 1.82 & 8.24 \\
Ketoconazole & 6.42 & 4.19 & 10.39 \\
Bifonazole & 6.36 & 5.23 & 2.66 \\
Econazole & 6.48 & 5.35 & 5.77 \\
Terconazole & 8.45 & 5.37 & 14.26 \\
Posaconazole & 14.85 & 5.41 & 8.15 \\
Isoconazole & 6.48 & 5.96 & 6.01 \\
Miconazole & 6.48 & 5.96 & 6.01 \\
Sertaconazole & 6.48 & 6.23 & 5.93 \\
Butoconazole & 6.51 & 6.55 & 5.52 \\
Fenticonazole & 6.48 & 6.94 & 4.16 \\
\hline
\end{tabular}

(*) MarvinSketch 19.24.0 (hpp:/ / www.chexon.com). $\left({ }^{* *}\right)$ HLB, hydrophilic-lipophilic balance).

\subsubsection{Effect of $\mathrm{pH}$ and Buffer Solution on Enantioseparation}

The analytes selected in this study had both neutral (the eight imidazole derivates) and markedly basic (the four triazole derivates) pKa values, as detailed in Table 1. Based on the chemical nature of the selector and that of the analytes, the $\mathrm{pH}$ of the mobile phase was expected to have an effect on their charge and, consequently, on their interactions. To investigate such aspects, aqueous solutions buffered at different $\mathrm{pH}$ levels were preparedammonium formate ( $\mathrm{pH}: 3)$, ammonium acetate $(\mathrm{pH}$ 6-7), and ammonium bicarbonate ( $\mathrm{pH}$ range 8-10) -all of them at a concentration of $5 \mathrm{mM}$. The chromatographic runs were performed in isocratic elution, using a mobile phase containing acetonitrile/buffered water $(75: 25, v / v)$. Figure 1 shows the effect on the enantiomeric resolution: as the $\mathrm{pH}$ increased, an improvement in chiral resolution could be observed up to $\mathrm{pH}$ 9, while a slight decrease appeared at $\mathrm{pH}$ 10. Compounds such as fluconazole, voriconazole, bifonazole, and posaconazole did not exhibit any enantiomeric separation throughout the explored $\mathrm{pH}$ range. With the exception of bifonazole, the basic nature of the other analytes was responsible for a strong electrostatic interaction with the CSP, which was not suitable for enantiomeric discrimination. At $\mathrm{pH} 9$, the uncharged form of the neutral fungicides enhanced their weak interactions with the selector, favoring their separation. On the other hand, the same result was not observed for bifonazole, probably because its structure lacks halogen atoms or other strongly electron-attracting groups. 


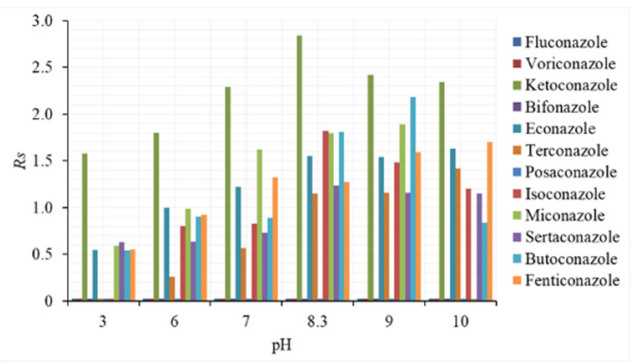

(a)

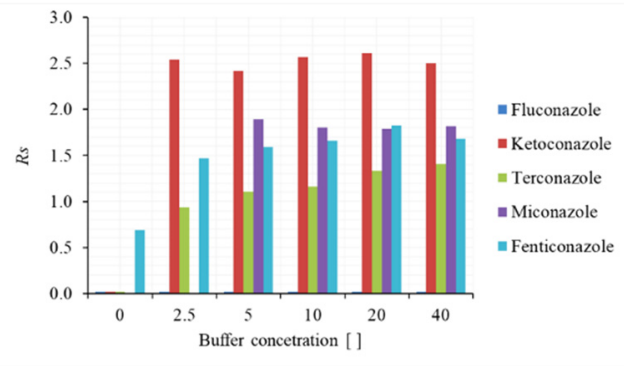

(b)

Figure 1. (a) Effect of buffer $\mathrm{pH}$ and (b) buffer concentration on enantioresolution (Rs) of some selected azole antifungal drugs. Chromatographic conditions: $75 \mu \mathrm{m}$ I.D. packed with i-CDCPCCPS $(5 \mu \mathrm{m})$ Lpack $=25 \mathrm{~cm}$, Leff $=26.5 \mathrm{~cm}$; mobile phase, $($ a) $5 \mathrm{mM}$ ammonium formate $(\mathrm{pH} 2.5$ and 3.5), ammonium acetate buffer ( $\mathrm{pH} 4.5$ and 5.5), ammonium hydrogen carbonate ( $\mathrm{pH} 8-10)$ in $\mathrm{ACN} /$ water $(75: 25, v / v),(\mathbf{b})$ ammonium hydrogen carbonate $(\mathrm{pH} 9)$ in $\mathrm{ACN} /$ water $(75: 25, v / v)$; flow rate, approximately $300-400 \mathrm{~nL} \mathrm{~min}^{-1}$; injected volume, approximately $100 \mathrm{~nL}$; sample concentration (racemic): $100 \mu \mathrm{g} \mathrm{mL}^{-1}$ in $\mathrm{ACN} /$ water or $\mathrm{MeOH} /$ water (50:50, v/v); detection wavelength: $195 \mathrm{~nm}$; room temperature. For other experimental conditions, see the text.

Considering the enantioselectivity (Rs), peak shape, and peak efficiency (data not shown), the best results were obtained at $\mathrm{pH}$ 9, in line with the findings of Zhang et al. [28], who obtained the baseline separation of some fungicides on a cellulose-based Chiralpak IC CSP using a HPLC system. Based on the obtained results, eight out of twelve analytes exhibited enantioselective interaction with the stationary phase under examination, namely miconazole, butoconazole, econazole, isoconazole, ketaconazole, sertaconazole, fenticonazole, and terconazole; however, only five of them were chosen as representative for further optimization experiments.

The following tests were aimed at verifying the effect of the buffer concentration in the range $2.5-40 \mathrm{mM}$. The increase in buffer concentration, and then in the mobile phase ionic strength, resulted in a general decrease in retention factors, suggesting the involvement of an ion exchange mechanism. Likewise, as shown in Figure 1b, the enantiomeric resolution was also improved, although no influence was observed for ketoconazole. It is clear that an unbuffered or low-concentration buffer mobile phase was not suitable for chiral discrimination, suggesting an important ionic interaction in diastereomeric complex formation between the CSP and the analytes. Finally, considering the better peak shape and the general improvement in peak efficiency (data not shown) for all the analytes, a buffered mobile phase of $20 \mathrm{mM}$ at pH 9 was selected as the best compromise between the considered parameters to conduct further studies.

\subsubsection{Effect of the Mobile Phase Composition: Water Content and Organic Modifier}

Keeping unchanged the buffer concentration $(20 \mathrm{mM}$ ammonium bicarbonate, $\mathrm{pH} 9)$, different $\mathrm{ACN} / \mathrm{H}_{2} \mathrm{O}$ ratios were tested, varying the water content from $15 \%$ to $40 \%(v / v)$. Since no appreciable effect was observed on chromatographic efficiency, the ACN/ $\mathrm{H}_{2} \mathrm{O}$ $85 / 15(v / v)$ ratio was chosen as the best compromise between Rs and the lowest analysis time.

The composition of the organic modifier was changed by testing mixtures composed of $\mathrm{ACN} / \mathrm{MeOH}$ in the range $0 / 85-85 / 0(v / v)$ and their effect on $\mathrm{k} 1$ and Rs was studied. As can be seen in the $\mathrm{k} 1$ plot in Figure 2a, a U-shaped profile was obtained, showing a minimum for intermediate $\mathrm{MeOH} / \mathrm{ACN}$ ratios. When the mobile phase was rich in $\mathrm{MeOH}$ or $\mathrm{ACN}$, the analytes had lower solubility in the mobile phase and showed greater affinity for the stationary phase. This trend appeared to be more marked for $\mathrm{MeOH}$ than $\mathrm{ACN}$, probably due to differences in their polarity and viscosity. The lower viscosity of ACN caused the analysis to be performed more quickly; moreover, being an aprotic solvent, its inability to form hydrogen bonds with the analytes favored their stereospecific interactions with the stationary phase (Figure $2 \mathrm{~b}$ ). Besides $\mathrm{MeOH}$, other solvents $(\mathrm{EtOH}$, i-prOH, and 
acetone) were used in combination with $90 \% \mathrm{ACN}$, but the best results were achieved through the individual employment of ACN as an organic modifier.
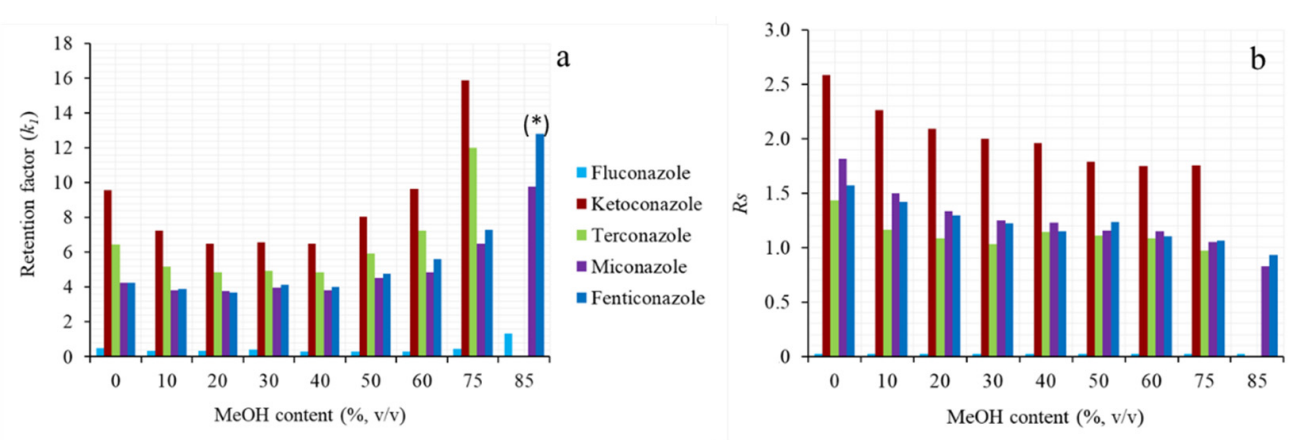

Figure 2. Effect of $\mathrm{MeOH}$ (in $\mathrm{ACN} / \mathrm{MeOH}$ ratio) content on (a) $\mathrm{k}_{1}$ and (b) enantioresolution of some selected azole antifungal drugs. Chromatographic conditions: $20 \mathrm{mM}$ ammonium hydrogen carbonate $(\mathrm{pH} 9)$ in organic phase/water $(85 / 15, v / v)$. >90 min analysis time for ketoconazole and terconazole.

\subsubsection{On-Column Pre-Concentration for Sensitivity Improvement}

Even if the use of a capillary column offers interesting advantages, such as higher peak efficiency and lower chromatographic dilution, the downscaling effect from a conventional chromatographic column to a capillary one requires an injection volume in the order of some tens of nanoliters. This limit, together with the reduced path length of on-column spectrophotometric detection (e.g., 75-100 $\mu \mathrm{m}$ ), makes it unsuitable for trace analysis and, therefore, other analytical options such as on-column pre-concentration procedures have been studied. This approach allows one to inject a large sample volume (overloading conditions) without affecting either the column performance or the chromatographic profile. This procedure can be pursued by selecting a sample dilution solvent with an elution power that is lower than that of the mobile phase. To this end, the racemic mixtures of the five selected azole compounds $\left(10 \mu \mathrm{g} \mathrm{mL}^{-1}\right)$ were dissolved in different solvents, such as the mobile phase, acetonitrile, methanol, water, $5 \mathrm{mM}$ of buffer, and 50/50 ACN/water; then, $200 \mathrm{~nL}$ was injected into the nano-LC system. Figure 3 shows that the best compromise in terms of low band broadening, sensitivity, and solubility was obtained with ACN/water $50 / 50(v / v)$. In fact, high water percentages improve the chromatographic efficiency and Rs but, at the same time, cause low peak areas, probably due to reduced analyte solubility. 


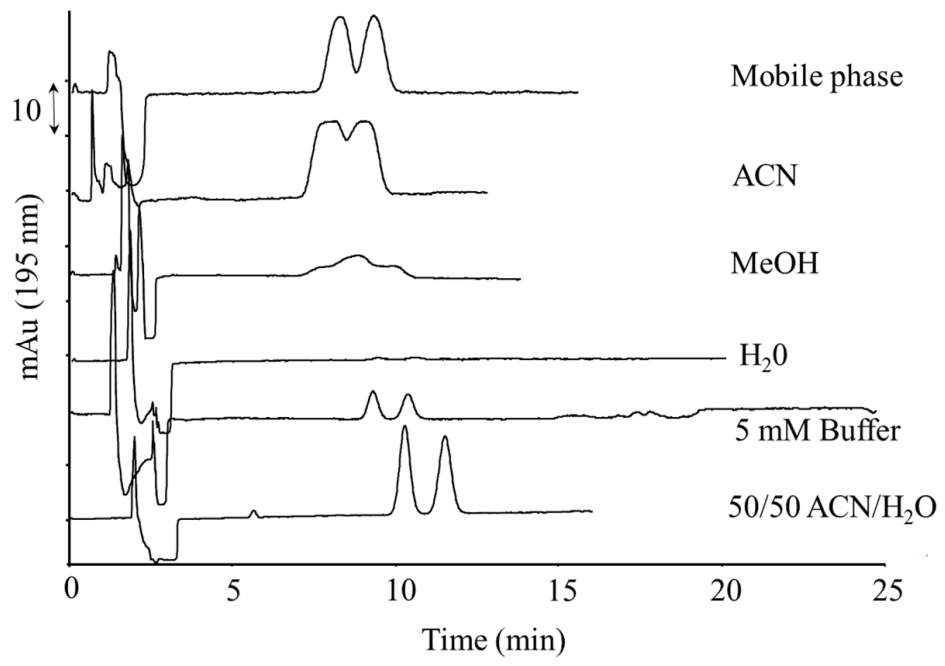

Figure 3. Effect of sample dilution solvent on the chromatographic profile of miconazole. Chromatographic conditions: $20 \mathrm{mM}$ ammonium hydrogen carbonate $(\mathrm{pH} 9)$ in $\mathrm{ACN} /$ water $(85 / 15, v / v)$; flow

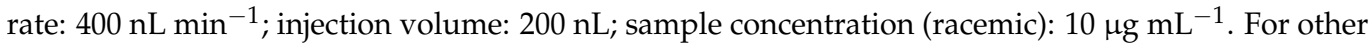
experimental conditions, see Figure 1 and text.

Afterwards, the effect of different injection volumes (range 60-800 nL) on the band wideness was investigated. To this end, the ratio between peak height $(\mathrm{H})$ and peak width at half height $\left(\mathrm{w}_{1 / 2}\right)$, i.e., $\mathrm{H} / \mathrm{w}_{1 / 2}$, was plotted versus the injection volume. Generally, as the injection volume increased, a corresponding increase in the chromatographic area was observed; in addition, if the band wideness did not change, the height of the peak increased too and a linear behavior was observed. Deviations from linearity occur when the on-column focusing effect is lost; thus, the maximum injectable volume can be derived from the highest point of the linear plot. Miconazole and butoconazole did not show deviations from linearity in the studied range (data not shown), while ketoconazole, terconazole, and fenticonazole exhibited important deviations above $400 \mathrm{~nL}$. Based on these results, the maximum injection volume was estimated as $300 \mathrm{~nL}$.

In conclusion, among the eight compounds individually separated at the baseline (Figure 4), four of them, namely econazole, miconazole, terconazole, and ketoconazole, could be simultaneously separated by the nano-LC-UV system. For this reason and due to their widespread use in veterinary medicine, they were selected to develop a fast, simple, and green method for their determination in milk samples. 

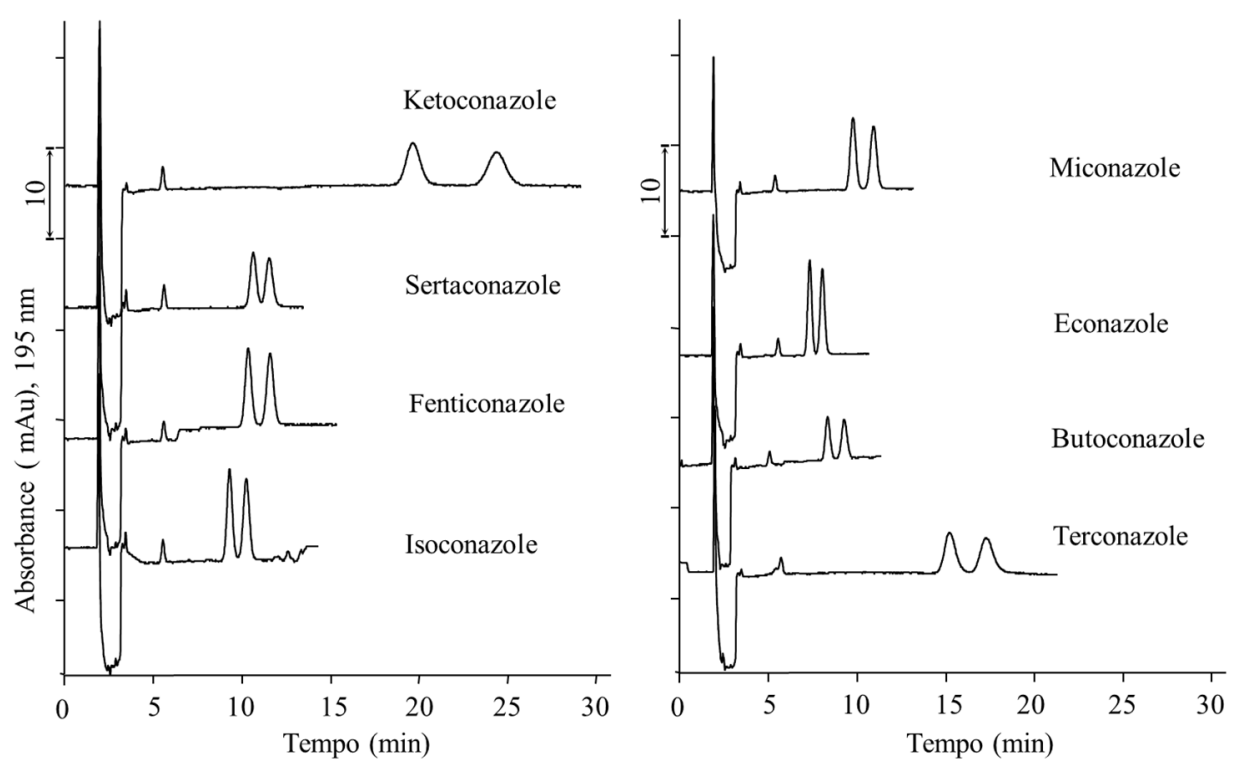

Figure 4. Nano-LC enantioseparation of the studied antifungal drugs. Chromatographic conditions: $20 \mathrm{mM}$ ammonium hydrogen carbonate $(\mathrm{pH} 9)$ in $\mathrm{ACN} /$ water $(85 / 15, v / v)$; flow rate: $400 \mathrm{~nL} \mathrm{~min}^{-1}$; injection volume: $300 \mathrm{~nL}$; sample concentration (racemic): $10 \mu \mathrm{g} \mathrm{mL}{ }^{-1}$. For other experimental conditions, see Figure 1 and text.

\subsection{Optimization of the Extraction Procedure}

In the optimal conditions of separation and injection, the nano-LC system was combined with an extraction procedure suitable for isolating econazole, miconazole, terconazole, and ketoconazole from milk samples. Initially, two miniaturized extractive techniques were compared: rotating-disc $\mu$-solid-phase extraction (disc $\mu$-SPE) based on buckypaper (BP) as the sorbent material and DLLME. To this end, preliminary experiments were carried out by using Milli-Q water $(10 \mathrm{~mL})$ spiked pre-extraction at $250 \mathrm{ng} / \mathrm{mL}$ with the four analytes. For each condition, three replicates were performed and recoveries were evaluated by comparison of the mean area with that obtained on a $10 \mathrm{~mL}$ Milli-Q water sample spiked post-extraction at the same level, according to the following equation:

$$
R \%=\frac{\overline{\text { Area }}_{\text {pre-extraction }}}{\text { Area }_{\text {post-extraction }}} \times 100
$$

The extraction of the target analytes was firstly performed by means of disc $\mu$-SPE [29-32]. Briefly, each SPE device was realized using a $25 \mathrm{~mm}$ diameter disc taken from a commercial BP sheet (Nanolab Inc. Waltham, MA, USA). BP is a nanostructured porous material, composed of multi-walled carbon nanotubes (MWCNTs) [33,34]. The BP disc was housed in a circle-shaped polypropylene mesh envelopment sealed at the circumference and with an open pouch to insert the disc. To ensure the disc's rotation, a $7 \mathrm{~mm}$ long magnetic bar was kept in a narrow polypropylene tube fixed on the top side of the BP holder. In order to enhance the hydrophilic properties of the BP, the SPE device was immersed in a nitric acid aqueous solution $(65 \%, v / v)$ for $8 \mathrm{~h}$ to functionalize the $\mathrm{BP}^{\prime} \mathrm{s}$ surface with carboxylic groups. Then, the material was rinsed with ultrapure water and $\mathrm{MeOH}$, in order to remove any traces of acid, as well as any original impurities [29]. At the end of the oxidation reaction and immediately before its use, the BP device was water-conditioned (with Milli-Q) for $10 \mathrm{~min}$ in a $50 \mathrm{~mL}$ Pyrex glass beaker.

Three cleaned SPE devices were placed into $25 \mathrm{~mL}$ beakers, each of them containing $10 \mathrm{~mL}$ of water spiked with the analytes, and left under continuous magnetic stirring at $100 \mathrm{rpm}$ overnight (16 h overall). Thereafter, the devices were removed using tweezers and dried thoroughly on sorbent paper. Finally, they were left under magnetic stirring (100 rpm) in $25 \mathrm{~mL}$ beakers containing $4 \mathrm{~mL}$ of $\mathrm{MeOH}$, The complete desorption of the 
analytes took place in $20 \mathrm{~min}$. The extracts were evaporated to dryness under a gentle nitrogen stream and each residue was reconstituted in $250 \mu \mathrm{L}$ of $\mathrm{ACN} / \mathrm{H}_{2} \mathrm{O}(85 / 15, v / v)$, centrifuged at 13,000 rpm for $10 \mathrm{~min}$, and then injected for nano-LC analysis.

The results showed that only econazole was recovered satisfactorily, with a mean yield of $85 \%$, while miconazole was isolated with a mean yield of $59 \%$. Terconazole and ketoconazole were not recovered at all. In a previous study [33], it was verified that compounds with $\log \mathrm{P}$ greater than 1.5 have a good affinity for BP depending on their $\mathrm{pKa}$ values. All analytes selected in this study had $\log P$ values in the range between 4.19 and 5.96, which does not justify the dramatic difference in the recovery values. A possible explanation was found when the hydrophilic-lipophilic balance (HLB) was taken into consideration. According to this index, compounds with an HLB value of approximately 6 , such as econazole and miconazole, can be considered hydrophobic, while an HLB greater than 10, such as in the case of terconazole and ketoconazole, indicates a hydrophilic character. The elution with methanol containing $10 \mathrm{mM}$ trimethylammonium chloride allowed us to recover terconazole at a percentage of less than $5 \%$.

Owing to these unsatisfying outcomes, the recovery study was performed through a DLLME procedure by using $\mathrm{CHCl}_{3}$ as an extracting solvent $(100,200$, and $300 \mu \mathrm{L})$ and $\mathrm{CH}_{3} \mathrm{CN}(500,800$ and $1000 \mu \mathrm{L})$ as a dispersing solvent. Among the different combinations, the best conditions were obtained with $300 \mu \mathrm{L}$ of $\mathrm{CHCl}_{3}$ and $500 \mu \mathrm{L}$ of $\mathrm{CH}_{3} \mathrm{CN}$. In this case, all analytes were recovered with the following mean yields: econazole at $85 \%$, miconazole at $100 \%$, terconazole at $68 \%$, and ketoconazole at $55 \%$.

Figure 5 compares the chromatographic profile of the standard working solution with those obtained after DLLME and disc $\mu$-SPE.

On the basis of these results, DLLME was selected for the extraction of antifungal drugs from milk samples. Based on our experience regarding the sample treatment of milk and milk derivatives [23,35-38], the protein precipitation was induced by acidified $\mathrm{ACN}$. In order to obtain the maximum protein removal, screening experiments were carried out on $3 \mathrm{~mL}$ of milk by adding ACN in different proportions (1:2, 1:3, and 1:4 v/v milk/solvent) and by testing different types and volumes of acid in the organic solvent (acetic acid or formic acid, 100-400 $\mu \mathrm{L}$ ). The best conditions were $6 \mathrm{~mL}$ of ACN (1:2 v/v sample/ACN) and $200 \mu \mathrm{L}$ of acetic acid. After centrifugation, the supernatant was taken and quickly concentrated at $40{ }^{\circ} \mathrm{C}$ under reduced pressure by means of a rotavapor. The aqueous residue (approximately $3 \mathrm{~mL}$ ) was diluted with Milli-Q water to a final volume of $10 \mathrm{~mL}$, quickly filtered through $0.45 \mu \mathrm{m}$ PTFE filters, and finally submitted to the DLLME procedure, previously optimized. Within the experimental error, recovery values from milk reflected the same percentage yields obtained from Milli-Q water. 


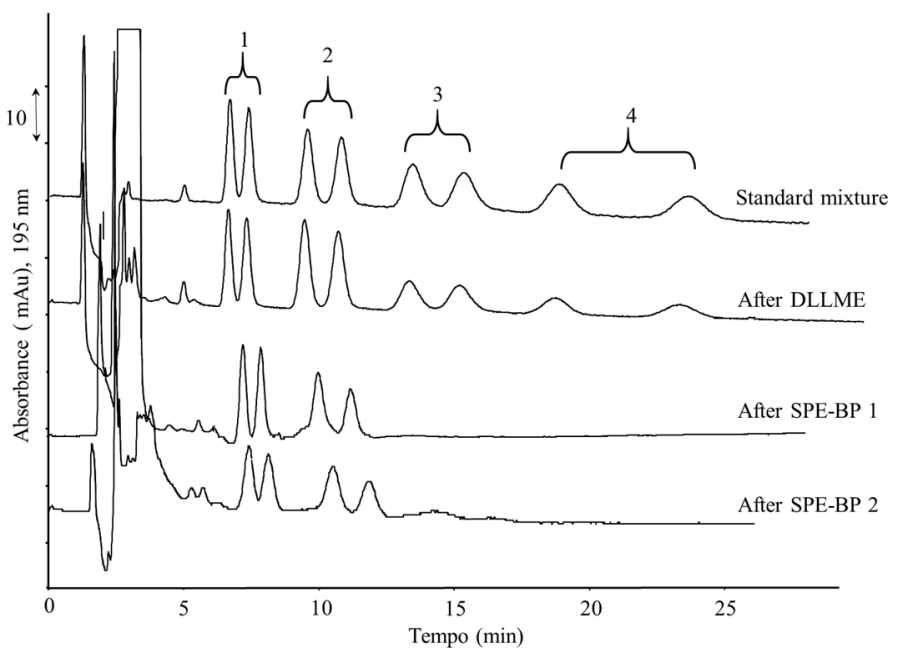

Figure 5. Chromatograms of Milli-Q water spiked with a multistandard solution: mix standard solution; DLLME with a mixture of $\mathrm{ACN} / \mathrm{CH}_{3} \mathrm{Cl}(500 / 300 \mu \mathrm{L})$ as the dispersing and extracting solvent, respectively; SPE-BP 1, with desorbing solvent $\mathrm{MeOH}$; SPE-BP 2 with desorbing solvent $\left[\left(\mathrm{CH}_{3}\right)_{4} \mathrm{~N}\right] \mathrm{Cl}$ hydrate $10 \mathrm{mM} \mathrm{MeOH}$. Experimental conditions: 1 -econazole, 2-miconazole, 3-terconazole, 4-ketoconazole.

\subsection{Validation of the DLLME-Nano-LC-UV Method}

Once optimized, the whole DLLME-nano-LC-UV method was validated considering the peak area and retention time repeatability, linear calibration range and sensitivity, LOD and LOQ, and precision and trueness.

For the intraday and interday repeatability, two blank milk samples were spiked preextraction at two concentration levels (level I 1.0-7.0 $\mu \mathrm{g} \mathrm{mL}^{-1}$ and level II, 1.5-10.0 $\mu \mathrm{g} \mathrm{mL}^{-1}$ ); each sample was injected six times $(n=6)$ on three consecutive days $(n=15)$. The resulting data are reported in detail in Table 2: the intraday and interday relative standard deviation (RSD\%) values for retention times were in the ranges of $1.3-4.9 \%$ and $5.2-6.4 \%$, respectively. In addition, RSD $\%$ values of peak areas ranged between $4.7 \%$ and $6.8 \%$ (intraday precision) and between $7.9 \%$ and $9.2 \%$ (interday precision), showing the repeatability of the developed chromatographic method, which is compatible with a non-thermostatic system. In addition, three columns were prepared following the same experimental conditions and tested in order to verify the reproducibility. The obtained results were quite satisfactory, with an RSD of the retention time $<7 \%$, while retention factors were in the range of $9-12 \%$.

Table 2. Peak area repeatability and reproducibility of spiked milk samples obtained with DLLMEnano-LC-UV method.

\begin{tabular}{|c|c|c|c|c|c|}
\hline \multirow[b]{3}{*}{ Peak } & & \multicolumn{4}{|c|}{ Peak Area (RSD, \%) } \\
\hline & & \multicolumn{2}{|c|}{ Level I $\left(3.0-7.0 \mu \mathrm{g} \mathrm{mL}^{-1}\right)$} & \multicolumn{2}{|c|}{ Level II $\left(6.0-15.0 \mu \mathrm{g} \mathrm{mL}^{-1}\right)$} \\
\hline & & Intraday $(n=6)$ & Interday $(n=15)$ & Intraday $(n=6)$ & Interday $(n=15)$ \\
\hline \#1 & Econazole & 6.4 & 9.2 & 6.5 & 9.0 \\
\hline \#2 & Econazole & 6.7 & 8.8 & 6.8 & 8.8 \\
\hline \#1 & Miconazole & 5.2 & 7.3 & 6.4 & 7.5 \\
\hline \#2 & Miconazole & 4.7 & 7.8 & 6.1 & 8.4 \\
\hline \#1 & Terconazole & 4.9 & 6.9 & 4.7 & 7.3 \\
\hline \#2 & Terconazole & 5.2 & 7.2 & 5.5 & 7.5 \\
\hline \#1 & Ketoconazole & 6.0 & 8.3 & 5.9 & 8.4 \\
\hline \#2 & Ketoconazole & 5.7 & 8.8 & 6.7 & 9.1 \\
\hline
\end{tabular}

Matrix-matched calibration curves were built by extracting six blank milk aliquots spiked pre-extraction with the target analytes at increasing concentrations $(0.5,1.5,3.0,5.0$, 7.0, $10.0 \mu \mathrm{g} \mathrm{mL}^{-1}$ ).

Table 3 lists the linear dynamic range, the slope of the calibration curve (sensitivity), and the determination coefficients $\left(\mathrm{R}^{2}\right)$, which were all higher than 0.990. LODs and LOQs 
were estimated by injecting extracts of blank milk aliquots spiked pre-extraction with decreasing concentrations of the target analytes until signal-to-noise ratios $(\mathrm{S} / \mathrm{N})$ of 3 and 10 were obtained, respectively. As shown in Table 3, the LODs and LOQs were in the low $\mu \mathrm{g} \mathrm{mL}^{-1}$ range.

Table 3. Linear dynamic range for the enantiomers of the selected target compounds in spiked milk samples after the sample pretreatment DLLME and analyzed by nano-LC-UV.

\begin{tabular}{|c|c|c|c|c|c|c|c|}
\hline \multirow[b]{2}{*}{ Peak \# } & \multirow[b]{2}{*}{ Analyte } & \multirow{2}{*}{$\begin{array}{c}\text { Linear Dynamic } \\
\text { Range } \\
\left(\mu \mathrm{g} \mathrm{mL}^{-1}\right)\end{array}$} & \multicolumn{2}{|c|}{$\begin{array}{l}\text { Regression Equation }(n=6) \\
y=m x+n\end{array}$} & \multirow[b]{2}{*}{$R^{2}$} & \multirow[b]{2}{*}{$\begin{array}{l}\text { LOD }^{\mathrm{a}}{ }_{\text {method }} \\
\left(\mu \mathrm{g} \mathrm{mL}{ }^{-1}\right)\end{array}$} & \multirow[b]{2}{*}{$\begin{array}{l}\mathrm{LOQ}^{\mathrm{b}}{ }_{\text {method }} \\
\left(\mu \mathrm{g} \mathrm{mL^{-1 } )}\right.\end{array}$} \\
\hline & & & $M \pm t \cdot S_{m}\left(10^{4}\right)$ & $\mathbf{N} \pm \mathbf{t} \cdot \mathrm{S}_{\mathrm{n}}\left(10^{4}\right)$ & & & \\
\hline 1 & \multirow{2}{*}{ Econazole } & $0.50-10.0$ & $1.9 \pm 0.8$ & $1.5 \pm 1.6$ & 0.990 & 0.05 & 0.14 \\
\hline 2 & & $0.50-10.0$ & $2.0 \pm 1.0$ & $1.2 \pm 1.4$ & 0.992 & 0.06 & 0.16 \\
\hline 1 & \multirow{2}{*}{ Miconazole } & $1.5-10.0$ & $2.3 \pm 1.1$ & $1.3 \pm 1.4$ & 0.991 & 0.20 & 0.80 \\
\hline 2 & & $1.5-10.0$ & $2.2 \pm 1.2$ & $1.1 \pm 1.2$ & 0.990 & 0.30 & 1.10 \\
\hline 1 & \multirow{2}{*}{ Terconazole } & $4.0-20.0$ & $1.8 \pm 0.8$ & $1.5 \pm 1.7$ & 0.990 & 1.10 & 3.20 \\
\hline 2 & & $4.0-20.0$ & $1.7 \pm 1.1$ & $1.7 \pm 1.8$ & 0.991 & 1.20 & 3.50 \\
\hline 1 & \multirow[b]{2}{*}{ Ketokonazole } & $7.0-20.0$ & $1.8 \pm 1.2$ & $1.1 \pm 1.3$ & 0.991 & 2.50 & 6.10 \\
\hline 2 & & $7.0-20.0$ & $1.9 \pm 1.3$ & $0.9 \pm 1.2$ & 0.992 & 2.70 & 6.80 \\
\hline
\end{tabular}

$\mathrm{m}$, slope; Sm, standard deviation of the slope; $\mathrm{n}$, intercept; $\mathrm{Sn}$, standard deviation of the intercept; $\mathrm{R}^{2}$, determination coefficient. (a) Calculated as the concentration associated with an $\mathrm{S} / \mathrm{N}$ ratio of 3 ; (b) Calculated as the concentration associated with an $\mathrm{S} / \mathrm{N}$ ratio of $10 . \mathrm{t}=$ (Student's $\mathrm{t}$ test $)=2.78, \alpha=0.05$.

Precision and accuracy were estimated at two different concentration levels (in the range of 3-15 $\mu \mathrm{g} \mathrm{mL}^{-1}$ ) by spiking preextraction six blank milk samples for each spike level. The experimental concentration was calculated from the calibration curves (Table 3) and then compared with the theorical one. The method's goodness was evaluated by Student's $\mathrm{t}$ test, matching the experimental $\mathrm{t}$ value with the tabulated one for $n=6\left(\mathrm{t}_{5}=2.57\right.$ for $n=6, p=0.05$ ). As shown in Table 4 , all experimental $t$ values were lower than $t_{5}$, with accuracy in the range of $89-119 \%$ and with repeatability lower than 19\% (see RSD values). Although these data can be accepted (accuracy, $80-120 \%$ and RSD $<20 \%$ ), importantly, the deviation could be affected by interferences in the studied matrix.

Table 4. Results of the precision and accuracy study of the DLLME-nano-LC-UV method on spiked milk samples. For experimental conditions, see Materials and Methods section.

\begin{tabular}{|c|c|c|c|c|c|}
\hline Analytes & Peak \# & $\begin{array}{l}\text { Spiked Level } \\
\left(\mu \mathrm{g} \mathrm{mL}^{-1}\right)\end{array}$ & $\begin{array}{l}\text { Found }^{(a)} \\
\left(\mu g \mathrm{~mL}^{-1}\right)\end{array}$ & $\begin{array}{l}\text { Accuracy (\%), } \\
\text { (RSD,\%) }\end{array}$ & $\mathbf{t}$ \\
\hline \multirow{4}{*}{ Econazole } & 1 & 3.0 & $2.7 \pm 0.3$ & 91 (19) & 0.69 \\
\hline & 2 & 5.0 & $5.2 \pm 0.6$ & $104(12)$ & 1.46 \\
\hline & 1 & 3.0 & $2.8 \pm 0.3$ & $92(17)$ & 1.98 \\
\hline & 2 & 5.0 & $5.4 \pm 0.2$ & $108(15)$ & 1.65 \\
\hline \multirow{4}{*}{ Miconazole } & 1 & 3.0 & $2.7 \pm 0.3$ & $89(12)$ & 0.66 \\
\hline & 2 & 5.0 & $4.8 \pm 0.4$ & 95 (17) & 0.37 \\
\hline & 1 & 3.0 & $2.8 \pm 0.8$ & $93(14)$ & 0.87 \\
\hline & 2 & 5.0 & $5.0 \pm 1.4$ & 99 (18) & 0.22 \\
\hline \multirow{4}{*}{ Terconazole } & 1 & 5.0 & $5.2 \pm 0.8$ & 104 (12) & 1.01 \\
\hline & 2 & 10.0 & $9.5 \pm 1.4$ & 95 (17) & 2.27 \\
\hline & 1 & 5.0 & $5.4 \pm 1.1$ & $108(15)$ & 2.39 \\
\hline & 2 & 10.0 & $9.2 \pm 1.5$ & $92(19)$ & 1.59 \\
\hline \multirow{4}{*}{ Ketokonazole } & 1 & 7.0 & $8.1 \pm 1.4$ & 115 (12) & 0.01 \\
\hline & 2 & 15.0 & $15.6 \pm 2.8$ & $104(14)$ & 2.51 \\
\hline & 1 & 7.0 & $8.3 \pm 1.6$ & $119(14)$ & 0.90 \\
\hline & 2 & 15.0 & $16.2 \pm 3.1$ & $108(16)$ & 1.93 \\
\hline
\end{tabular}

(a). Average value \pm confidence interval (five determinations, 95\% confidence value) $t=($ Student's $t$ test $)=2.56$ $\alpha=0.05$. 
Finally, Figure 6 shows the chromatographic profiles obtained after the DLLME-nanoLC-UV analysis of a milk sample spiked with the selected compounds (a) and of a blank milk sample (b).

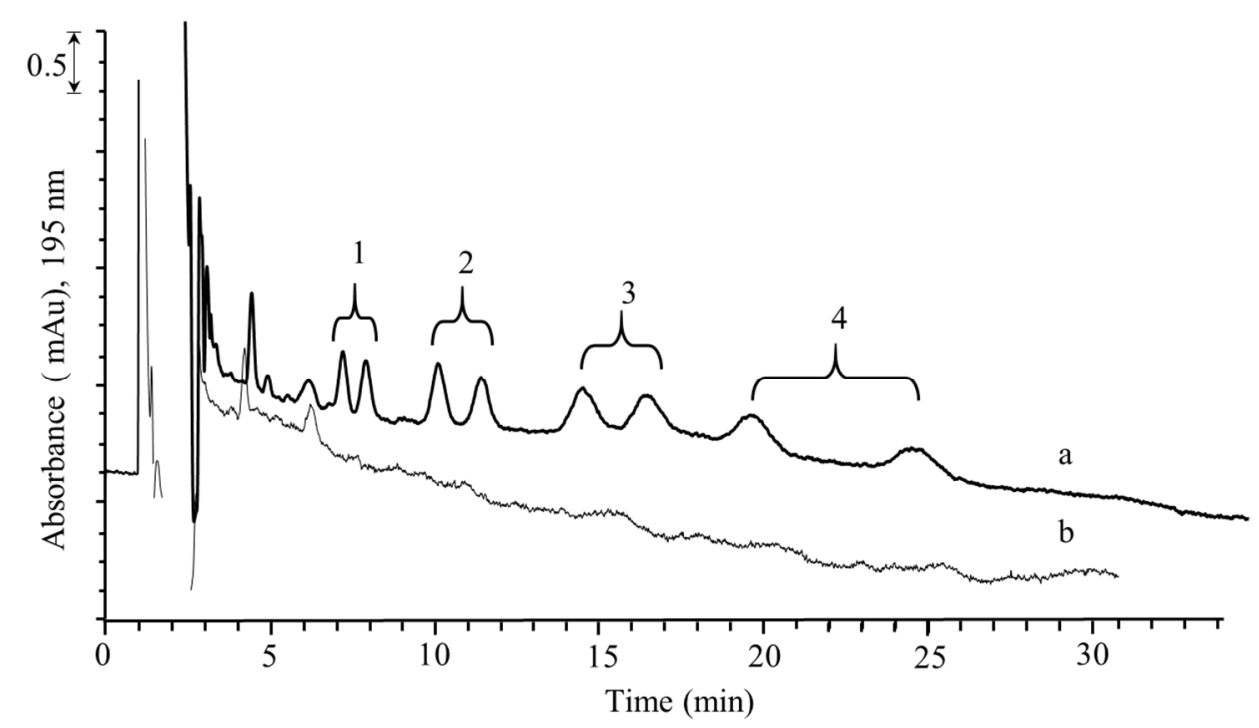

Figure 6. UV chromatograms of milk samples after DLLME-nano-LC-UV method: (a) spiked with selected antifungal drugs, (b) blank sample. Experimental conditions: spiked racemic mixture 5-15 $\mu \mathrm{g} / \mathrm{mL}$ ng. For further information, see Figure 5 and text.

\subsection{Comparison with Other Methods}

To the best of our knowledge, the literature on the determination of antifungal drugs in milk and dairy samples is quite limited. Thus far, only two papers dealing with this topic have achieved higher sensitivity. For instance, by using GC-FID combined with three-phase HF-LPME, miconazole showed an LOD of 4-6 $\mathrm{ng} \mathrm{mL}^{-1}$ and a recovery of 103.2-109.6. Combining USAE-D- $\mu$-SPE based on a mesoporous carbon sorbent with HPLCDAD analysis resulted in ketoconazole and miconazole recoveries of $83.3-111.1 \%$ and LODs in the range of $0.15-3.0 \mathrm{ng} \mathrm{mL}^{-1}$ [8]. However, although the HF-LPME method produced high sensitivity and extraction efficiency, it required a longer extraction time of up to $40 \mathrm{~min}$.

The superior sensitivity achieved on a conventional LC column or GC-FID can also be explained considering the achiral chromatographic analysis of the two above-mentioned methods: for each analyte, both enantiomers co-elute, providing greater area and S/N ratios. On the other hand, the method presented here is the first application for the chiral nano-LC analysis of antifungal drugs in milk samples. This preliminary approach could be improved in the future by the development of a more sensitive hyphenation with a mass spectrometry detector.

\section{Materials and Methods}

\subsection{Chemicals and Reagents}

All chemicals were of analytical reagent RS grade and used without further purification. Acetone, acetonitrile $(\mathrm{ACN})$, chloroform, ethanol $(\mathrm{EtOH})$, methanol $(\mathrm{MeOH})$, 2-propanol (2-PrOH), ammonium hydrogen carbonate $\left(\mathrm{NH}_{4} \mathrm{HCO}_{3} \geq 99.0 \%\right.$, w/w), ammonia solution $(30 \%, w / w)$, glacial acetic acid $(99.0 \%, w / w)$, formic acid $(99.0 \%, w / w)$ (FA), and trimethylammonium chloride were purchased from Aldrich-Fluka-Sigma S.r.1. (Milan, Italy). Ultrapure water was produced by a Milli-Q Plus system from Millipore (Bedford, MA, USA).

The following standard racemic mixtures (purity $\geq 97 \%$ ) were obtained from AldrichFluka-Sigma S.r.l. (Milano, Italy): bifonazole (1-(p, $\alpha$-diphenylbenzyl)imidazole) (CAS, 6062896-8), butoconazole (( \pm )-1-[4-(4-chlorophenyl)-2-[(2,6-dichlorophenyl)thio]butyl]-1H-imidazole 
mononitrate) (CAS, 67085-13-6), econazole (1-(2-((4-chlorophenyl)methoxy)-2-(2,4dichlorophenyl)ethyl)-1H-imidazole) (CAS, 27220-47-9), fenticonazole ((RS)-1-[2-(2,4dichlorophenyl)-2-hydroxyethyl]-3-[4-(phenylsulphanyl)benzyl]imidazolium nitrate) (CAS, 72479-26-6), fluconazole (2-(2,4-difluorophenyl)-1,3-bis(1H-1,2,4-triazol-1-yl)propan-2-ol) (CAS, 86386-73-4), ketoconazole $(( \pm)$-cis-1-acetyl-4-(4-[(2-[2,4-dichlorophenyl]-2-[1H-imidazol-1ylmethyl]-1,3-dioxolan-4-yl)-methoxy]phenyl)piperazine) (CAS,265-667-4), isoconazole (1[2-(2,4-dichlorophenyl)-2-[(2,6-dichlorophenyl)methoxy]ethyl]-1H-imidazole) (CAS, 2752340-6), miconazole (( \pm )-1-[2-(2,4-dichlorobenzyloxy)-2-(2,4-dichlorophenyl)ethyl]-1Himidazole) (CAS, 22916-47-8), posaconazole (4-[4-[4-[4-[[(3R,5R)-5-(2,4-difluorophenyl)-5(1,2,4-triazol-1-ylmethyl)oxolan-3-yl]methoxy]phenyl]piperazin-1-yl]phenyl]-2-[(2S,3S)-2hydroxypentan-3-yl]-1,2,4-triazol-3-one) (CAS, 171228-49-2), sertaconazole (1-(2-((7chlorobenzo[b]thiophen-3-yl)methoxy)-2-(2,4-dichlorophenyl)ethyl)-1H-imidazole) (CAS, 99592-32-2), terconazole (1-(4-((2-(2,4-dichlorophenyl)-2-(1H-1,2,4-triazol-1-ylmethyl)-1,3dioxolan-4-yl)methoxy)phenyl)-4-(1-methylethyl)piperazine) (CAS, 67915-31-5) and voriconazole (2R,3S-2-(2,4-difluorophenyl)-3-(5-fluoropyrimidin-4-yl)-1-(1H-1,2,4-triazol-1-yl)butan2-ol) (CAS, 137234-62-9).

Commercial buckypaper was purchased from Nanolab, Inc. (Nanolab, Waltham, MA, USA).

The standard stock solutions were prepared at a concentration of $1 \mathrm{mg} \mathrm{mL}^{-1}$, by dissolving in $\mathrm{MeOH}$ weighted amounts of the analytes (Ohaus DV215CD Discovery semimicro and analytical balance, $81 / 210 \mathrm{~g}$ capacity, $0.01 / 0.1 \mathrm{mg}$ readability) in volumetric flasks. The multi-standard working solutions $\left(100\right.$ or $\left.10 \mu \mathrm{g} \mathrm{m}^{-1}\right)$ were prepared by diluting the individual stock solutions with $\mathrm{ACN} /$ water 50/50 $(v / v)$.

The buffer solutions $(50 \mathrm{~mL}, 500 \mathrm{mM}$ ammonium acetate, formate, or hydrogen carbonate) were prepared by dissolving the proper amount of ammonium salt in ultrapure water and by adjusting the $\mathrm{pH}$ with $5 \mathrm{M}$ ammonia or formic acid. The mobile phases were daily prepared by diluting the appropriate amount of buffer solution in $\mathrm{ACN} /$ water mixture.

The standard stock solutions were stored in $1.5 \mathrm{~mL}$ Eppendorf tubes (Eppendorf S.r.l., Milano, Italy) at $-18{ }^{\circ} \mathrm{C}$. The working standard mixtures, buffer solutions, and sample extracts were stored in the dark at $4{ }^{\circ} \mathrm{C}$ prior to their use or analysis.

\subsection{The Nano-LC System}

Nano-LC experiments were performed using a semi-laboratory-assembled instrumentation composed of an Ultimate ${ }^{\mathrm{TM}}$ Capillary HPLC unit from LC Packings Dionex (Amsterdam, The Netherlands), equipped with a flow splitting unit and a nano injector valve (Enantiosep, Münster, Germany; https:/ / patents.google.com/patent/DE102 $60700 \mathrm{~A} 1 / \mathrm{de})$ joined to the pump through a PEEK capillary tube $(40 \mathrm{~cm} \times 130 \mu \mathrm{m}$ I.D., Vici Valco Houston, TX, USA). The injected volume was established by using the pressurepulse-driven technique and estimated from the injection time and the column flow rate of the mobile phase [39]. Its external configuration included a $50 \mu \mathrm{L}$ loop acting as both sample loading and mobile phase reservoir during the chiral separation. The micro-pump was used in isocratic mode delivering $\mathrm{MeOH}$, while the internal split solvent was recycled as a pump solvent reservoir. The column flow rate was checked by connecting a $10 \mu \mathrm{L}$ syringe (Hamilton, Reno, NV, USA) to the column outlet through a Teflon ${ }^{\circledR}$ tube (TF-350, LC-Packing, CA, USA) and by measuring the mobile phase volume for approximately $5 \mathrm{~min}$.

A UV-VIS HPE 100 BIO-RAD (Hercules, CA, USA) instrument was employed for the on-capillary UV detection. The detector was set at $195 \mathrm{~nm}$; the rise time was adjusted at $0.3 \mathrm{~s}$. The LC pump was manually controlled. The UV detector's electric signal was acquired and processed by the software Chromatography Data System N2000 (Dual Channels) (BaseLine Chromtech, Zhejiang University, Republic of China).

A $75 \mu \mathrm{m}$ I.D. capillary column, packed for $25 \mathrm{~cm}$ length with CDCPC $5 \mu \mathrm{m}$ particle size, was used for the chiral separation of all the studied antifungal drugs. The chromatograms 
were achieved in isocratic mode by using as the mobile phase a $5 \mathrm{mM}$ ammonium hydrogen carbonate $\mathrm{ACN} / \mathrm{H}_{2} \mathrm{O}, 85 / 15(v / v)$ mixture ( $\left.\mathrm{pH} 8.2\right)$, at a flow rate of $400 \mathrm{~nL} \mathrm{~min}{ }^{-1}$.

\subsection{Chiral Stationary Phase and Packing of Capillary Column}

The chiral selector used in this study was cellulose 3,5-dichlorophenylcarbamate (CDCPC) covalently bonded to $5 \mu \mathrm{m}$ silica particles. This material was provided by Enantiosep GmbH (Münster, Germany).

The chiral columns were prepared in our laboratory by packing the CSP into polyimide outside-coated fused-silica capillaries ( $375 \mu \mathrm{m}$ O.D. and $75 \mu \mathrm{m}$ I.D. from Polymicro TechnologiesTM, CM Scientific Ltd., Silsden, UK), according to the slurry packing method [40]. An LC series 10 HPLC pump (Perkin Elmer, Palo Alto, CA, USA) was utilized for packing the fused-silica capillary and for the fast equilibration of the capillary column. The capillary column was packed for $25 \mathrm{~cm}$, while the detection window was prepared at an effective length of $26.5 \mathrm{~cm}$. The total length was approximately $35 \mathrm{~cm}$. The capillary was quickly conditioned with the mobile phase at $20 \mathrm{MPa}$ and, thereafter, it was ready to be used in the nano-LC system. The success of the procedure, both in terms of homogeneous distribution of the stationary phase and sealing of the capillary through the localized fusion of silica, was checked by means of a Stereozoom 4 optical microscope (Cambridge Instruments, Vienna, Austria) with an illuminator.

\subsection{Milk Samples}

The whole cow pasteurized milk samples analyzed in this study were purchased in local supermarkets in Rome, Italy.

The method was validated on whole cow milk with a percentage composition in terms of proteins, carbohydrates, and fats of 3.4, 4.8, and $3.6(w / v)$, respectively.

\subsection{Sample Preparation}

The analyte extraction was performed according to a two-step protocol: protein precipitation and DLLME.

The milk was initially allowed to equilibrate at room temperature; then, the carton was shaken and a $3 \mathrm{~mL}$ aliquot was introduced in a $15 \mathrm{~mL}$ polypropylene centrifuge tube (Biofil ${ }^{\circledR}$, Alicante, Spain). Upon the addition of $6 \mathrm{~mL}$ of ACN and $200 \mu \mathrm{L}$ of acetic acid, protein precipitation was triggered and completed, keeping the mixture under magnetic stirring for $15 \mathrm{~min}$. The suspension was then centrifuged at $4000 \mathrm{rpm}(3000 \times \mathrm{g})$ for 10 min (Universal 320R centrifuge Hettich ${ }^{\circledR}$, Merck KGaA, Darmstadt, Germany), and the supernatant was transferred into a $25 \mathrm{~mL}$ evaporating flask to be evaporated at $40{ }^{\circ} \mathrm{C}$ with a rotavapor R-200 (Büchi Labortechnik, Flawil, Switzerland). The obtained aqueous residue (approx. $3 \mathrm{~mL}$ ) was diluted with Milli-Q water to a final volume of $10 \mathrm{~mL}$, filtered through $0.45 \mu \mathrm{m}$ PTFE filters (Sartorius, Goettingen, Germany), and subjected to the microextraction procedure. To this end, a mixture of $500 \mu \mathrm{L}$ of $\mathrm{ACN}$ (as the dispersion solvent) and $300 \mu \mathrm{L}$ of $\mathrm{CHCl}_{3}$ (as the extraction solvent) was rapidly introduced into the aqueous sample by means of a $1 \mathrm{~mL}$ calibrated micropipette. The sample was vortex-shaken for $2 \mathrm{~min}$ (Reax 2000, Heidolph Instruments GmbH \& CO, Germany) and then centrifuged at $4000 \mathrm{rpm}$ for $5 \mathrm{~min}$. After this, the chlorinated solvent containing the target analytes was withdrawn with a micro-syringe at the tube bottom. The extract $(200 \mu \mathrm{L})$ was evaporated to dryness under a gentle nitrogen stream and the residue was reconstituted in $250 \mu \mathrm{L}$ of $\mathrm{ACN} / \mathrm{H}_{2} \mathrm{O}(50 / 50$, $v / v$ ) and injected into the nano-LC system.

\subsection{Method Validation}

The DLLME-nano-LC-UV method was validated in a matrix following the main FDA guidelines for the bioanalytical methods [41].

To this end, the main evaluated parameters were recovery, precision, accuracy, sensitivity, linearity, and selectivity. All the statistical analyses were carried out using the nu- 
merical data analysis method included in Excel software (Microsoft Office 2013, Redmond, WA, USA)

\section{Conclusions}

A lab-made nano-LC-UV system has been applied for the first time to the chiral separation of some racemic mixtures of imidazole and triazole derivatives. A $75 \mu \mathrm{m}$ I.D. capillary column packed with a CSP-polysaccharide base (cellulose 3,5-dichlorophenylcarbamate, CDCPC) allowed us to achieve a baseline enantioresolution of 8 out of 12 racemic mixtures, four of which were separated in less than $25 \mathrm{~min}$ at approximately $400 \mathrm{~nL} \mathrm{~min}^{-1}$.

These results attest to the great potential of enantioselective nano-LC, which is a rapid and green method for chiral separation, requiring small amounts of solvent and sample. Moreover, only a few milligrams of CSP material is sufficient for packing different columns. The nano-LC represents a cheaper alternative to the conventional HPLC and an interesting testbench of new, often expensive, stationary phases. This miniaturized chromatographic technique has been here combined with a miniaturized sample preparation technique (DLLME), making the developed method even greener. The application of this method to milk samples provides reliable information about the occurrence of individual stereoisomers, representing a useful tool to better understand stereoselective transfer and bioaccumulation processes.

Author Contributions: Writing—editing—-methodology, data curation, C.D.B.; validation—formal analysis-investigation, F.B.; writing-supervision, A.G.; writing-review and editing, C.F.; conceptualization - writing—original draft preparation, G.D. All authors have read and agreed to the published version of the manuscript.

Funding: This research received no external funding.

Institutional Review Board Statement: Not applicable.

Informed Consent Statement: Not applicable.

Data Availability Statement: Not applicable.

Acknowledgments: We sincerely thank Bezhan Chankvetadze for providing the chiral stationary phase used in this study. The authors would like to dedicate this experimental work to Salvatore Fanali, whose long career has been dedicated to miniaturized chromatographic and electromigration techniques. His professional life as a researcher is characterized by international scientific successes and collaborations all over the world, as well as friendships; however, above all, he is a mentor to dozens of students and co-workers.

Conflicts of Interest: The authors declare no conflict of interest.

Sample Availability: Not applicable.

\section{References}

1. Hector, R.F. An overview of antifungal drugs and their use for treatment of deep and superficial mycoses in animals. Clin. Tech. Small Anim. Pract. 2005, 20, 240-249. [CrossRef]

2. Van Den Bossche, H.; Engelen, M.; Rochette, R. Antifungal agents of use in animal health-chemical, biochemical and pharmacological aspects. J. Vet. Pharmacol. Ther. 2003, 26, 5-29. [CrossRef]

3. Rochette, F.; Engelen, M.; Vanden Bossche, H. Antifungal agents of use in animal health-practical applications. J. Vet. Pharmacol. Ther. 2003, 26, 31-53. [CrossRef]

4. Farajzadeh, A.; Mogaddam, M.R.; Ghorbanpour, H. Development of a new microextraction method based on elevated temperature dispersive liquid-liquid microextraction for determination of triazole pesticides residues in honey by gas chromatographynitrogen phosphorus detection. J. Chromatogr. A. 2014, 1347, 8-16. [CrossRef] [PubMed]

5. Ebrahimpour, B.; Yamini, Y.; Esrafili, A. Extraction of azole antifungal drugs from milk and biological fluids using a new hollow fiber liquid-phase microextraction and analysis by GC-FID. Chromatographia 2011, 74, 281-289. [CrossRef]

6. Toribio, L.; del Nozal, M.J.; Bernal, J.L.; Alonso, C.; Jiménez, J.J. Enantiomeric separation of several antimycotic azole drugs using supercritical fluid chromatography. J. Chromatogr. A 2007, 1144, 255-261. [CrossRef]

7. Liu, C.; Liao, Y.; Huang, X. Extraction of triazole fungicides in environmental waters utilizing poly (ionic liquid)-functionalized magnetic adsorbent. J. Chromatogr. A 2017, 1524, 13-20. [CrossRef] [PubMed] 
8. Othman, N.; Lim, V.; Ramachandran, M.R.; Sanagi, M.M.; Kamaruzaman, S.; Hirota, Y.; Norikazu, N.; Noorfatimah, Y.; Yahaya, N. Rapid ultrasound-assisted emulsification microextraction combined with COU-2 dispersive micro-solid phase extraction for the determination of azole antifungals in milk samples by HPLC-DAD. Chromatographia 2017, 80, 1553-1562. [CrossRef]

9. Wang, X.; Qi, P.; Zhang, H.; Xu, H.; Wang, X.; Li, Z.; Wang, Z.; Wang, Q. Enantioselective Analysis and Dissipation of Triazole Fungicide Penconazole in Vegetables by Liquid Chromatography-Tandem Mass Spectrometry. J. Agric. Food Chem. 2014, 62, 11047-11053. [CrossRef]

10. Zhang, Z.; Zhang, Q.; Gao, B.; Gou, G.; Li, L.; Shi, H.; Wang, M. Simultaneous enantioselective determination of the chiral fungicide prothioconazole and its major chiral metabolite prothioconazole-desthio in food and environmental samples by ultra performance liquid chromatography-tandem mass spectrometry. J. Agric. Food Chem. 2017, 65, 8241-8247. [CrossRef] [PubMed]

11. Qiu, J.; Dai, S.; Zheng, C.; Yang, S.; Cai, T.; Bie, M. Enantiomeric separation of triazole fungicides with $3 \mu \mathrm{m}$ and $5 \mu \mathrm{m}$ particle chiral columns by reverse-phase high performance liquid chromatography. Chirality 2011, 23, 479-486. [CrossRef] [PubMed]

12. Li, Y.; Dong, F.; Liu, X.; Xu, J.; Li, J.; Kong, Z.; Chen, X.; Liang, X.; Zheng, Y. Simultaneous enantioselective determination of triazole fungicides in soil and water by chiral liquid chromatography/tandem mass spectrometry. J. Chromatogr. A. 2012, 1224, 51-60. [CrossRef] [PubMed]

13. Ye, X.; Ma, S.; Zhang, L.; Zhao, P.; Hou, X.; Zhao, L.; Liang, N. Trace enantioselective determination of triazole fungicides in honey by a sensitive and efficient method. J. Food Compos. Anal. 2018, 74, 62-70. [CrossRef]

14. Ahmed, M.; Ghanem, A. Chiral $\beta$-cyclodextrin functionalized polymer monolith for the direct enantioselective reversed phase nano liquid chromatographic separation of racemic pharmaceuticals. J. Chromatogr. A 2014, 1345, 115-127. [CrossRef]

15. Ghanem, A.; Ahmed, M.; Ishii, H.; Ikegami, T. Immobilized $\beta$-cyclodextrin-based silica vs polymer monoliths for chiral nano liquid chromatographic separation of racemates. Talanta 2015, 132, 301-314. [CrossRef]

16. Fouad, A.; Shaykoon, M.S.A.; Ibrahim, S.M.; El-Adl, S.M.; Ghanem, A. Colistin Sulfate Chiral Stationary Phase for the Enantioselective Separation of Pharmaceuticals Using Organic Polymer Monolithic Capillary Chromatography. Molecules 2019, 24, 833. [CrossRef] [PubMed]

17. Fouad, A.; Marzouk, A.A.; Ibrahim, S.M.; El-Adl, S.M.; Ghanem, A. Functionalized polymer monoliths with carbamylated amylose for the enantioselective reversed phase nano-liquid chromatographic separation of a set of racemic pharmaceuticals. $J$. Chromatogr. A 2017, 1515, 91-99. [CrossRef]

18. Ahmed, M.; Yajadda, M.M.; Han, Z.J.; Su, D.; Wang, G.; Ostrikov, K.K.; Ghanem, A. Single-walled carbon nanotube-based polymer monoliths for the enantioselective nano-liquid chromatographic separation of racemic pharmaceuticals. J. Chromatogr. A 2014, 1360, 100-109. [CrossRef]

19. Jesús Valimaña-Traverso, J.; Morante-Zarcero, S.; Pérez-Quintanilla, D.; García, M.Á.; Sierra, I.; Marina, L.M. Periodic mesoporous organosilica materials as sorbents for solid-phase extraction of drugs prior to simultaneous enantiomeric separation by capillary electrophoresis. J. Chromatogr. A 2018, 1566, 135-145. [CrossRef]

20. Abdel-Megied, A.M.; Hanafi, R.S.; Aboul-Enein, H.Y. A chiral enantioseparation generic strategy for anti-Alzheimer and antifungal drugs by short end injection capillary electrophoresis using an experimental design approach. Chirality 2018, 30, 165-176. [CrossRef]

21. Rousseau, A.; Gillotin, F.; Chiap, P.; Bodoki, E.; Crommen, J. Generic systems for the enantioseparation of basic drugs in NACE using single-isomer anionic CDs. J. Pharm. Biomed. Anal. 2011, 54, 154-159. [CrossRef]

22. Gentili, A.; Caretti, F.; Bellante, S.; Rocca, L.M.; Curini, R.; Venditti, A. Development and validation of two multiresidue liquid chromatography tandem mass spectrometry methods based on a versatile extraction procedure for isolating non-steroidal anti-inflammatory drugs from bovine milk and muscle tissue. Anal. Bioanal. Chem. 2012, 404, 1375-1388. [CrossRef]

23. Caretti, F.; Gentili, A.; Ambrosi, A.; Rocca, L.M.; Delfini, M.; Di Cocco, M.E.; D'Ascenzo, G. Residue analysis of glucocorticoids in bovine milk by liquid chromatography-tandem mass spectrometry. Anal. Bioanal. Chem. 2010, 397, 2477-2490. [CrossRef]

24. Pérez-Fernández, V.; García, M.Á.; Marina, M.L. Chiral separation of agricultural fungicides. J. Chromatogr. A 2011, 1218, 6561-6582. [CrossRef] [PubMed]

25. Chankvetadze, B.; Yasima, E.; Okamoto, Y. Dimethyl-, dichloroand chloromethyl-phenylcarbamate derivatives of amylose as chiral stationary phases for high performance liquid chromatography. J. Chromatogr. A 1995, 694, 101-109. [CrossRef]

26. Chankvetadze, B.; Yashima, E.; Okamoto, Y. Chloromethylphenylcarbamate derivatives of cellulose as chiral stationary phases for high-performance liquid chromatography. J. Chromatogr. A 1994, 670, 39-49. [CrossRef]

27. Zhu, B.; Zhao, F.; Yu, J.; Wang, Z.; Song, Y.; Li, Q. Chiral separation and a molecular modeling study of eight azole antifungals on the cellulose tris(3,5-dichlorophenylcarbamate) chiral stationary phase. New J. Chem. 2018, 42, 13421-13429. [CrossRef]

28. Zhang, J.; Sun, J.; Liu, Y.; Yu, J.; Guo, X. Immobilized Cellulose-Based Chiralpak IC Chiral Stationary Phase for Enantioseparation of Eight Imidazole Antifungal Drugs in Normal-Phase, Polar Organic Phase and Reversed-Phase Conditions Using HighPerformance Liquid Chromatography. Chromatographia 2019, 82, 649-660. [CrossRef]

29. Tomai, P.; Martinelli, A.; Gasperi, T.; Bianchi, M.; Purcaro, V.; Teofili, L.; Papacci, P.; Cori, M.S.; Vento, G.; Curini, R.; et al. Rotating-disc micro-solid phase extraction of F2-isoprostanes from maternal and cord plasma by using oxidized buckypaper as sorbent membrane. J. Chromatogr. A 2019, 1586, 30-39. [CrossRef] [PubMed]

30. Tomai, P.; Gentili, A.; Fanali, S.; Picó, Y. Multi-residue determination of organic micro-pollutants in river sediment by stir-disc solid phase extraction based on oxidized buckypaper. J. Chromatogr. A 2010, 1621, 461080. [CrossRef] 
31. D'Orazio, G.; Fanali, C.; Gentili, A.; Tagliaro, F.; Fanali, S. Nano-liquid chromatography for enantiomers separation of baclofen by using vancomycin silica stationary phase. J. Chromatogr. A 2019, 1605, 360358. [CrossRef]

32. Tomai, P.; Gentili, A.; Curini, R.; Gottardo, R.; Tagliaro, F.; Fanali, S. Dispersive liquid-liquid microextraction, an effective tool for the determination of synthetic cannabinoids in oral fluid by liquid chromatography-tandem mass spectrometry. J. Pharm. Anal. 2020, 11, 292-298. [CrossRef]

33. Tomai, P.; Martinelli, A.; Morosetti, S.; Curini, R.; Fanali, S.; Gentili, A. Oxidized buckypaper for stir-disc solid phase extraction: Evaluation of several classes of environmental pollutants recovered from surface water samples. Anal. Chem. 2018, 90, 6827-6834. [CrossRef] [PubMed]

34. Pérez-Fernández, V.; Gentili, A.; Martinelli, A.; Caretti, F.; Curini, R. Evaluation of oxidized buckypaper as material for the solid phase extraction of cobalamins from milk: Its efficacy as individual and support sorbent of a hydrophilic-lipophilic balance copolymer. J. Chromatogr. A 2016, 1428, 255-266. [CrossRef]

35. D'Orazio, G.; Rocchi, S.; Fanali, S. Nano-liquid chromatography coupled with mass spectrometry: Separation of sulfonamides employing non-porous core-shell particles. J. Chromatogr. A 2012, 1255, 277-285. [CrossRef] [PubMed]

36. D'Orazio, G.; Hernández-Borges, J.; Vicente Herrera-Herrera, A.; Fanali, S.; Rodríguez-Delgado, M.Á. Determination of estrogenic compounds in milk and yogurt samples by hollow-fibre liquid-phase microextraction-gas chromatography-triple quadrupole mass spectrometry. Anal. Bioanal. Chem. 2016, 408, 7447-7459. [CrossRef]

37. D'Orazio, G.; Asensio-Ramos, M.; Hernández-Borges, J.; Rodríguez-Delgado, M.A.; Fanali, S. Evaluation of the combination of a dispersive liquid-liquid microextraction method with micellar electrokinetic chromatography coupled to mass-spectrometry for the determination of estrogenic compounds in milk and yogurt. Electrophoresis 2015, 36, 615-625. [CrossRef] [PubMed]

38. Gentili, A.; Miccheli, A.; Tomai, P.; Baldassarre, M.E.; Curini, R.; Pérez-Fernández, V. Liquid chromatography-tandem mass spectrometry method for the determination of vitamin K homologues in human milk after overnight cold saponification. J. Food Compos. Anal. 2016, 47, 21-30. [CrossRef]

39. Manz, A.; Simon, W. Injectors for open-tubular column liquid chromatography with 106 theoretical plates at retention times in the minute range. J. Chromatogr. A 1987, 387, 187-196. [CrossRef]

40. D'Orazio, G.; Fanali, C.; Karchkhadze, M.; Chankvetadze, B.; Fanali, S. Enantiomeric separation of some chiral analytes using amylose 3,5-dimethylphenylcarbamate covalently immobilized on silica by nano-liquid chromatography and capillary electrochromatography. J. Chromatogr. A 2017, 1520, 127-134. [CrossRef] [PubMed]

41. Hill, H.M. Bioanalytical methods validation: A critique of the proposed FDA guidance. Chromatographia 2000, 52, S65-S69. [CrossRef] 